\title{
PRODUÇÃO ESCRITA EM LÍNGUA ESPANHOLA E PRÁTICAS DE LETRAMENTO CRÍTICO NO PROJETO CASAS DE CULTURA NO CAMPUS ${ }^{1}$
}

\section{WRITTEN PRODUCTION IN SPANISH LANGUAGE AND CRITICAL LITERACIES PRACTICES IN THE CASAS DE CULTURA NO CAMPUS PROJECT}

\author{
Andrey Ronald Monteiro da Silva" \\ Flávia Colen Meniconi ${ }^{* *}$ \\ Sérgio Ifa"***
}

Resumo: Esta investigação se propôs a trabalhar com o desenvolvimento da criticidade dos alunos a partir de sequências didáticas de leitura, discussão oral e produção escrita no idioma espanhol. Como pressupostos teóricos, apoiamo-nos nos estudos da escrita como processo (BROKES; GRUNDY, 1988; MADRIGAL ABARCA, 2008; FLOWER; HAYES, 1981; 1996) e nas teorias relacionadas ao Letramento crítico (JANKS, 2016; MATTOS; VALÉRIO, 2010; SANTOS; IFA, 2013). O estudo teve como base metodológico a pesquisa narrativa (ARAGÃO, 2008; CLANDININ; CONNELLY, 2011; SAHAGOFF, 2015), na qual atuamos como professores/pesquisadores e analisamos tanto o desenvolvimento dos alunos, no que diz respeito ao conhecimento da língua, a argumentação e criticidade, quanto o nosso próprio desenvolvimento. Este trabalho demonstrou que o ensino pode ir além do foco gramatical e caminhar em direção a uma proposta mais discursiva que possibilite a formação cidadã, crítica e reflexiva.

Palavras-chave: Língua espanhola; Escrita como processo; Letramento crítico.

Aвstract: This study aimed to investigate the development of the students' criticality from didactic sequences of Reading, oral and written productions in the Spanish

\footnotetext{
${ }^{1}$ Este artigo é resultado de uma pesquisa de iniciação científica (PIBIC), financiada pela CAPES e aprovada pelo comitê de ética sob o número 34095114.3.0000.5013.

" Professor de Língua Espanhola do Projeto Casas de Cultura no Campus e mestrando em Linguística Aplicada do Programa de Pós-Graduação em Linguística e Literatura da FALE/UFAL (PPGLL). E-mail: andrey.silva@fale.ufal.br.

" Professora Doutora de Língua Espanhola do Curso de Letras/Espanhol (FALE/UFAL), coordenadora do Projeto Casas de Cultura no Campus (Língua Espanhola) e professora do Programa de Pós-Graduação em Linguística e Literatura (PPGLL/FALE/UFAL).E-mail: flavia.meniconi@fale.ufal.br.

**** Professor Doutor de Língua Inglesa do Curso de Letras/Inglês (FALE/UFAL), coordenador geral do Projeto Casas de Cultura no Campus e professor do Programa de Pós-Graduação em Linguística e Literatura (PPGLL/FALE/UFAL). E-mail: sergio@fale.ufal.br.
} 
language. As theoretical underpinnings, we studied writing as a process (BROKES; GRUNDY, 1988; MADRIGAL ABARCA, 2008; FLOWER; HAYES, 1981; 1996) and the critical literacy perspective (JANKS, 2016; MATTOS; VALÉRIO, 2010; SANTOS; IFA, 2013). The research was based on the narrative research method (RAGAO, 2008, CLADININ; CONNELLY, 2011; SAHAGOFF, 2015). Where we, teachers and researchers, analyzed both the development of students, with regard to language knowledge, argumentation and criticality, as well as our own development. This work demonstrated that teaching could go beyond the grammatical focus and move towards a more discursive proposal that enables citizenship critical and reflective education.

KEYWoRDs: Spanish; Writing as a process; Critical literacy perspective.

\section{INTRODUÇão}

A língua adicional ${ }^{2}$ possui um importante papel na construção e aprimoramento da formação do ser humano, uma vez que seu envolvimento o ajuda a "aumentar sua autopercepção como ser humano e cidadão, [...] pela aprendizagem ele aprende mais sobre si mesmo e sobre um mundo plural, marcado por valores culturais diferentes" (BRASIL, 1998, p. 19). Assim, acreditamos que seja essencial reconhecer a necessidade de um processo de ensino-aprendizagem de línguas adicionais que vá além da exposição exclusiva às regras gramaticais e ortográficas, uma vez que, em nossa concepção, os conhecimentos e os usos dos idiomas têm como objetivo levar as pessoas a agirem na sociedade (BRASIL, 1998, p. 23), como "forma de participação social onde ocorre a construção do conhecimento compartilhado” (TILIO, 2014, p. 931).

Nessa perspectiva, Tilio (2014) argumenta que a aprendizagem é constituída a partir de três tipos de conhecimentos: o conhecimento sistêmico da língua, conhecimento de organização textual e o conhecimento do mundo. Para o autor, é importante não só tornar o aluno apto a se comunicar, mas, também, possibilitá-lo o acesso a discursos em uma língua que servirão para empoderá-lo. Conhecer esses novos discursos pode capacitar o alunado à resistência e à construção de uma outra globalização, que "ao invés de globalizar a hegemonia, realmente abarca a pluralidade e a diversidade” (TILIO, 2014, p. 931).

Além disso, os nossos discursos internalizados possibilitarão a interação com pessoas de outras culturas, visto que as sociedades já não sobrevivem isoladamente, mas por meio de relações entre si que atravessam as fronteiras geopolíticas e culturais, em busca de uma comunicação e o entendimento mútuo. Dentro dessa perspectiva, consideramos que, no ensino de línguas, as relações que podem ser estabelecidas entre a língua alvo e a inclusão social objetivam "o desenvolvimento da consciência do papel das línguas na sociedade e o reconhecimento da diversidade cultural” (MULIK, 2011, p. 12).

\footnotetext{
${ }^{2}$ Moreira Junior (2016, p. 20) concebe língua adicional como "um produto ideológico que foi adicionado ao repertório linguístico-discursivo do falante ou que está em processo de construção para atender suas necessidades como condição para suas práticas sociais. Não como língua do outro, objetificada".
} 
Para tanto, embasamo-nos em estudos acerca da escrita como processo (BROKES; GRUNDY, 1988; MADRIGAL ABARCA, 2008; FLOWER; HAYES, 1981; 1996), do Letramento crítico (JANKS, 2016; MATTOS; VALÉRIO, 2010; SANTOS; IFA, 2013) e do ensino da escrita como processo em língua espanhola (MENICONI, 2015, 2017; FEITOSA; MENICONI; IFA, 2020). Este arcabouço teórico nos auxiliou na interpretação e compreensão mais profunda dos dados relacionados ao ensino-aprendizagem da língua espanhola, coletados em uma turma do nível básico do Projeto Casas de Cultura no Campus, da Universidade Federal de Alagoas, direcionado para uma formação crítica, discursiva e transformadora.

A seguir, apresentamos as teorias que embasaram o presente trabalho. Discorremos sobre os pressupostos do Letramento Crítico (JANKS, 2016; MATTOS; VALÉRIO, 2010; SANTOS; IFA, 2010) e suas considerações para o processo de construção e reconstrução de significados. Como também, a escrita como processo (BROKES; GRUNDY, 1988; MADRIGAL ABARCA, 2008; FLOWER; HAYES, 1981; 1996), entendendo o ato da escrita não somente como um jogo de regras gramaticais e ortográficas, como também constituído por dimensões psicológicas e sociais (MENICONI, 2017).

\section{LETRAMENTO CRÍTICO E A PROPOSTA DE ENSINO-APRENDIZAGEM DA ESCRITA EM LÍNGUA ESPANHOLA}

Segundo Mattos e Valério (2010), o modelo tradicional de ensino promove a perpetuação das relações de poder e de desigualdade, devido a conformação do alunado e a privação das oportunidades para questionamentos. Libâneo (1985) afirma que esse modelo sustenta a ideia de escola como preparadora de indivíduos para o desenvolvimento de papéis sociais, de acordo com as aptidões individuais. Por isso, as pessoas precisam aprender a se adaptar aos valores e às normas vigentes na sociedade de classes através do desenvolvimento da cultura individual. Além disso, os conteúdos são separados da experiência do aluno e das realidades sociais, valendo apenas o conhecimento do professor como uma verdade incontestável que, por sua vez, deve ser absorvida pelos alunos.

A perspectiva do Letramento Crítico tem o objetivo inverso, porque está associado à ideia de "empoderamento do sujeito" que se apropria de seu processo educacional para tomar iniciativas, exercitar sua intuição, criatividade e sentir-se confiante a engajar-se nas atividades comunicativas das aulas (MATTOS; VALERIO, 2010). Para Santos e Ifa (2013), esta perspectiva teórica também empodera o sujeito por meio da problematização da significação atribuída às palavras. Para os autores, as palavras carregam os significados atribuídos pelas pessoas, como apresentado por Bakhtin (1992). Ainda segundo Bakhtin, entender a língua como um discurso significa a impossibilidade da dissociação de seus falantes e dos atos, dos campos sociais e dos valores ideológicos que a norteiam (FILHO; TORGA, 2011 apud ARAUJO, 2018). 
Nesse sentido, defendemos que, no processo de ensino-aprendizagem de idiomas, devemos levar em consideração não somente o texto enquanto produto de interpretação, mas, também, de análise, considerando aspectos de seu entorno. Em outras palavras, é importante compreender como o texto foi escrito, para quem foi escrito, a realidade de quem o escreve e de seu possível leitor, pois não existe neutralidade no ato composicional (JANKS, 2016). Nessa perspectiva, Lopes (2020) argumenta que o letramento crítico conduz o processo de reflexão e questionamento, auxiliando o estudante "a tornar-se dono de suas próprias escolhas, sem a influência de manifestações homogêneas e essencialistas que ainda hoje afetam o imaginário de muitas pessoas" (LOPES, 2020, p. 13). Acrescentamos ainda que é por meio da leitura crítica que reconhecemos que os textos são representações parciais do mundo. Para confirmar este posicionamento, Stella e Ifa (2014, p. 169) "consideram textos como objetos ideológicos, situados, parciais e, por isso, contestáveis".

Portanto, concebemos, aqui, uma definição de texto que vai além da produção escrita como produto, mas qualquer unidade de sentido que transmita alguma informação como uma imagem, uma música, entre outros (KOCH; TRAVAGLIA, 1992).

\section{A ESCRITA COMO PROCESSO}

A produção de textos, seja em qualquer nível de educação, não é uma atividade de fácil realização, pois, segundo Marchusci (2010), a escrita é uma das habilidades mais complexas de produção textual-discursiva e de uso da língua. É nesta perspectiva que a construção de sentidos e a produção escrita seguem as orientações da abordagem da escrita como processo, que pode ser descrita, de acordo com Campbell e Ifa (2016, p. 129) como aquela abordagem que "diverge a escrita do texto de uma para várias etapas, não concentrando-se apenas em um produto final", mas no processo pelo qual se conquista esse objetivo. Na visão de Brokes e Grundy (1988, p. 15), interessa a todos a capacidade de elaboração de "produtos finais imaginativos, seguros, pessoais e públicos fluídos e sem erros". No entanto, alguns professores solicitam a criação de diversos produtos e esperam que a repetição, auxiliada por marcações e avaliação, resultará em um produto aceitável, porém, muitas vezes, sem a percepção do quão interessante e efetivo pode ser todo o processo.

Segundo Madrigal Abarca (2008), é devido a essa situação que muitos estudiosos e professores preferem abordar um modelo com ênfase no aspecto cognitivo presente no ato da escrita. Esse modelo, denominado de Enfoque Processual, centra-se nas diferentes atividades do pensamento superior, presentes no processo da composição da escrita, desde o surgimento da circunstância social, que exige tal produção, até a sua finalização. Deste modo, a produção escrita não é vista como um produto finalizado, mas como um processo que implica elementos externos, como a motivação para a escrita, bem como elementos internos advindos da mente do escritor. Como afirmado por Meniconi (2017, p. 27), durante o processo da escrita, os 
escritores não só articulam elementos linguísticos no processo criativo frasal, em fragmentos e parágrafos, como também apresentam as formas de enxergar e entender o mundo por meio de suas concepções, ideias e argumentos.

No modelo de Flower e Hayes (1996), ao iniciar o processo composicional, o escritor deve atentar-se para o problema retórico, já que a produção textual demanda o empenho para resolver ou responder ao problema retórico por meio da escrita. Ainda para os autores, há três elementos presentes no processo da escrita: "o conteúdo da tarefa, a memória a longo prazo do escritor e o processo da escrita” (FLOWER; HAYES, 1981, p. 369). O primeiro elemento está relacionado ao problema retórico. Segundo Flower e Hayes (1981), resolver esse problema re-quer o conhecimento da situação em que o texto deverá ser produzido, o leitor, os objetivos da escrita e do escritor. O segundo refere-se à memória a longo prazo, na qual está armazenado o conhecimento sobre o tema, o leitor e os planos composicionais. Já o terceiro elemento diz respeito ao processo de redação, em que se incluem os processos básicos de planejamento, a escrita e a revisão. Durante o processo de planejamento, os escritores idealizam uma representação do conhecimento que será utilizado durante a redação. Este processo é, provavelmente, mais abstrato do que a representação escrita, por exemplo, "se poderia representar uma rede completa de ideias com uma só palavra” (FLOWER; HAYES, 1996, p. 7). Este também representa o momento em que se originam outros subprocessos, como "a geração de ideias, a formulação de objetivos e a avaliação das produções” (MENICONI, 2017, p. 31).

Além de considerar a influência da cognição para o processo da escrita adequada, torna-se necessário levar em conta, também, o ato composicional como uso e prática social da linguagem, uma vez que se configura como uma prática discursiva inseparável do contexto a partir do qual foi gerado e suas múltiplas funções. Os professores, engajados nas práticas de letramento, não só se preocuparão com o processo da produção textual com coesão e coerência, mas, principalmente, com o conteúdo presente nas composições, pois ali se encontram opiniões, crenças e valores defendidos (MENICONI, 2017; FEITOSA, MENICONI, IFA, 2020). Ao alunado, esta seria uma maneira de contribuir para a produção de textos bem articulados e, ao mesmo tempo, para a sua formação crítica, reflexiva e autônoma.

Apresentaremos, a seguir, a pesquisa narrativa enquanto proposta metodológica que direcionou tanto o desenvolvimento desta pesquisa quanto os procedimentos de coleta e interpretação de dados.

\section{Metodologia}

A metodologia adotada neste estudo foi a pesquisa narrativa (CLANDININ; CONNELLY, 2011). Segundo os autores, a pesquisa narrativa compreende a "uma forma de entender a experiência humana"(p.20) por meio de um processo dinâmico de viver e contar histórias, bem como de revivê-las e recontá-las. Não só as histórias dos alunos participantes, mas a dos pesquisadores. 
Para tanto, faz-se necessário o destaque de alguns termos, como o pessoal e o social, para tratar do processo de interação; o passado, presente e o futuro para a noção de continuidade; e, por último, o lugar como marcação para a situação. Os participantes da pesquisa devem ser entendidos como indivíduos, sempre em interação com outros e inseridos em um contexto social. Estes, conjuntamente, formam o espaço tridimensional que deve ser considerado na pesquisa narrativa (SAHAGOFF, 2015).

No contexto da aprendizagem, o termo experiência é um fator importante para a metodologia. Para Clandinin e Connelly (2011), a experiência é pessoal e social, visto que tanto o pessoal - sentimentos, esperanças, desejos, ideologias, disposição moral - como o social "condições existenciais, o ambiente, forças e fatores subjacentes e pessoas que participam e formam o contexto dos indivíduos" (SAHAGOFF, 2015, p. 3) - estão sempre presentes. Além disso, para Dewey (apud CLANDININ; CONNELLY, 2011), um dos critérios da experiência é a continuidade, ou seja, "a experiência se desenvolve a partir de outras experiências e de que experiências levam a outras experiências", onde quer que o indivíduo se posicione nesse continuum - o imaginado agora, no passado ou em um futuro - há sempre uma experiência passada como base e cada ponto levará a uma experiência futura (DEWEY apud CLANDININ; CONNELLY, 2011, p. 30).

Assim, a pesquisa narrativa se apresenta como um processo contínuo da negociação da convivência, no qual o pesquisador mergulha em um turbilhão de histórias e de ações; vive sua própria história e as histórias dos outros, procurando conexões, padrões e sentidos nas histórias relatadas, experiências vividas e observadas. É uma imersão nas dimensões temporais, contextuais e pessoais durante o processo de coleta de dados (ARAGAO, 2008).

No que tange a esta pesquisa, especificamente, realizamos nosso estudo no Projeto Casas de Cultura no Campus (CCC), um projeto de extensão da Universidade Federal de Alagoas que, por sua vez, tem como objetivo contribuir para a formação de professores de língua espanhola e difundir o ensino do idioma para discentes matriculados em diferentes cursos de graduação e alunos de escolas públicas.

O CCC oferece cursos de línguas adicionais de forma gratuita. As matrículas dos alunos interessados em estudar no projeto são realizadas por meio de respostas à formulários online divulgados por editais que, por sua vez, são publicados semestralmente. Os alunos podem iniciar os estudos a partir dos níveis básicos ofertados pelo projeto, sendo também possível a realização de testes de níveis para o acesso às turmas mais avançadas. O projeto atende a diferentes idades, uma vez que recebe tanto os alunos provenientes de escolas públicas, quanto estudantes matriculados em diferentes cursos da Universidade Federal de Alagoas.

O projeto Casas de Cultura no Campus coloca em xeque o ensino tradicional, voltado exclusivamente para o ensino de estruturas linguísticas do idioma, convidando os professores em formação inicial a caminharem em direção ao ensino-aprendizagem do idioma espanhol por uma perspectiva crítica e discursiva. Em outras palavras, ao fazer parte do CCC-Espanhol, 
somos desafiados a buscar novas propostas de ensino mais significativas para os alunos e direcionadas à formação reflexiva e transformadora.

Esta pesquisa foi desenvolvida em uma turma de nível básico, de fevereiro a maio de 2018, com duas aulas por semana, de 100 minutos cada uma delas. A turma estava composta por 12 alunos, sendo 5 estudantes da graduação de diversas áreas e 7 estudantes de escolas do ensino médio públicas de Maceió. Foram utilizados para coleta de dados: 6 planos de aula, 6 diários reflexivos do professor-pesquisador, gravações das aulas, conversas no WhatsApp e 50 produções escritas. Os temas trabalhados foram estereótipos, preconceito, drogas, violência de gênero, feminicídio e a maternidade. A seguir apresentaremos a discussão acerca dos dados coletados a partir do trabalho desenvolvido no CCC.

\section{INTERPRETAÇÃO DOS DADOS}

A interpretação dos dados será dividida em quatro subseções. Nas duas primeiras, interpretamos os dados relacionados aos dois temas discutidos nas aulas: homofobia e feminicídio. Nas duas últimas, interpretamos a criticidade no processo de escrita e os resultados e impactos dos alunos sobre a experiência vivida.

\section{NO TIENE LA CULPA}

A primeira aula temática ${ }^{3}$, intitulada como No tiene la culpa foi desenvolvida a partir de uma canção de Romeo Santos, que aborda a temática da homofobia. A ideia central da canção é a história do filho de Sofia e Dom Miguel, Manuel, um homossexual afeminado que sofre preconceito diariamente. Sua mãe o aceita e o ama, no entanto, seu pai é um homem machista, anti-gay, expressando que, na bíblia, nenhum "marica" entra no reino dos céus. Sobre seu uso em sala de aula, inicialmente, trabalhamos aspectos relativos à compreensão da canção, por meio do uso de estratégias de identificação das ideias gerais e específicas da letra. Posteriormente, promovemos a discussão sobre o conteúdo temático da música. Nessa discussão, experiências pessoais e sociais puderam ser identificadas em fragmentos gravados durante as aulas, como no exemplo a seguir:

Paulo4: A mí no me gusta la idea que dos personas del mismo sexo se relacionen. Professor Andrey: Por qué?

\footnotetext{
${ }_{3}^{3}$ Segundo Tapia e Fita (2009), a construção de uma abordagem temática, com a participação dos alunos, se caracteriza positivamente, visto que a utilização de temas do interesse dos alunos auxilia no desenvolvimento das capacidades linguísticas, além de propiciar maior motivação. Isso pode ser identificado nas tarefas produzidas pelos alunos e nos comentários que verbalizavam sobre, às vezes, aspectos delicados e dificilmente tratados em uma sala de aula e que apresentamos nesta seção. ${ }^{4}$ Usamos de nomes fictícios para preservar as identidades dos participantes da pesquisa.
} 
Paulo: En mi vida, yo no tengo experiencias con gays, hasta porque yo no tengo amigos gays.

Bruno: Yo pasé por diversas situaciones en la vida, ya he sido llamado de varias bromas, al salir con amigos, muchas personas hablaban "allá el viadito".

Professor Andrey: ¿En serio?

Bruno: Sí, pero hoy en día no, yo aprendí a ser fuerte y a defenderme, hasta que se den cuenta de que todos merecemos respeto. No puedo quedarme callado después de ser juzgado de cualquier nombre simplemente por el hecho de amar a alguien del mismo sexo (Gravação da aula, 2018).

Entendemos que o aluno Paulo ${ }^{5}$ não aceita a relação de dois homens e justifica seu posicionamento esclarecendo que, até aquele momento da aula, não tinha convivido com amigos homossexuais. Bruno ${ }^{6}$, por outro lado, revela que sofreu preconceito por ser homossexual, durante vários momentos de sua vida. Nas palavras do estudante, ao sair com seus amigos, era apontado por diversas pessoas como "viadinho". Mas, aprendeu a ser forte e a defender-se, pois não pode calar-se simplesmente pelo fato de amar a alguém do mesmo sexo. Enquanto professores-pesquisadores, seus comentários nos causaram orgulho, por ser tão jovem e tão consciente, além de vermos nele a oportunidade de possibilitar a (re)construção de significados em seu colega, como também nos demais.

Paulo: Profesor, entendí que la vida de los gays, es una vida dificil, de acuerdo con la sociedad machista en que vivimos actualmente. Los gays tienen muchos problemas, como los padres anti-gays, machistas y también los problemas de violencia. Y es necesario respétalos (Gravação da aula, 2018).

O excerto de Paulo, proveniente de uma conversa pessoal gravada antes do início da aula, revela uma nova visão sobre o tema. Acreditamos que a construção de significados aconteceu por conta da troca de experiências que lhe possibilitaram refletir sobre a realidade vivida, visto que "crescemos inconscientemente absorvendo os discursos das pessoas ao nosso redor" (JANKS, 2016, p. 31). Ressaltamos que essa absorção precisa ser refletida e analisada quando confrontada com outros posicionamentos, pontos de vistas e ideologias. Entendemos, assim, que os momentos de reflexão propiciados pelas aulas possibilitaram ao aluno compreender as dificuldades da vida de um homossexual que, em seu ponto de vista, é devido à sociedade machista em que vivemos. Além de afirmar a necessidade do respeito para com o outro.

\footnotetext{
${ }^{5}$ Um jovem de 19 anos, heterossexual e estudante de Meteorologia da UFAL.

${ }^{6}$ Um jovem de 15 anos, homossexual e estudante de uma escola pública de Maceió.
} 


\section{ME GRITARON NEGRA}

O tema foi gerado por um vídeo elaborado pelo parlamento europeu para homenagear a morte da vereadora Mariele Franco, socióloga, feminista, política brasileira e militante dos direitos humanos, assassinada no dia 14 de março de 2018, vítima do feminicídio. Nesse momento, lembramo-nos que, durante nossa aula temática, lemos e discutimos um poema de Victoria de Santa Cruz, Me gritaron negra7 , quando refletíamos sobre o preconceito social contra a mulher negra. Identificamos que nossa aula contribuiu para a discussão na rede social. Segue os excertos da discussão desenvolvida pelo grupo.

Figura 1 - Discussão realizada pelo grupo em rede social.
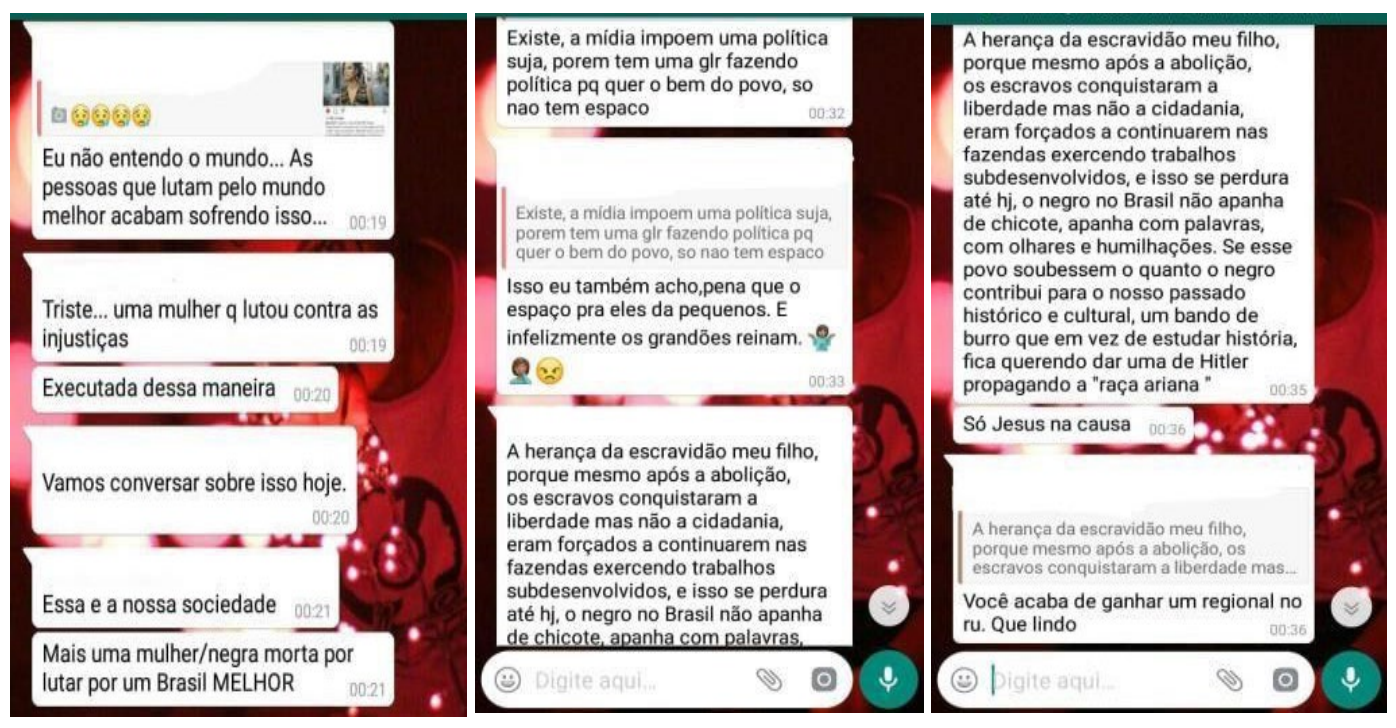

Fonte: Autores, 2018.

Nas trocas de mensagens, percebemos que os alunos se sentiram confortáveis para expor suas opiniões e posições acerca da temática. Traços de criticidade puderam ser identificados quando os alunos questionaram a sociedade brasileira que bate palmas para a agressão contra professores, questionam o feminicídio da mulher negra, questionam a mídia que, segundo um dos participantes da pesquisa, impõe uma política suja. Tal análise nos leva a concordar com Janks (2016, p. 29) quando afirma que "para aqueles que detêm o poder, é mais fácil mantê-lo se puderem persuadir todos na sociedade que não há nada de antinatural”.

Segundo a aluna Tatiana, em outro momento da conversa, "a relação de poder entre a minoria e os poderosos, negros e brancos, é uma herança deixada pelo passado, um preconceito ocasionado pela antiga geração e que se perdura até hoje” (conversa pelo whatsapp, 2018).

${ }^{7}$ Poema escrito em referência a experiência de preconceito vivido dentro de um grupo de amigos, ainda quando criança, simplesmente por ser negra. 
Para a jovem, é a herança da escravidão, justificando ainda que, mesmo após a conquista da liberdade, a cidadania pelos negros não foi alcançada, porque ainda continuaram exercendo trabalhos menos importantes e, hoje em dia, não mais apanham de chicote, mas apanham com olhares de superioridade de alguns e sofrem humilhações veladas.

É possível identificar que além de se situarem, com argumentos historicamente construídos, os alunos expressam formas de percepção do mundo, produzindo sentidos e interferindo na sua realidade social, por meio do questionamento e discutindo sobre as injustiças sociais historicamente marcadas pelo privilégio de um, em detrimento de outros (MOTTA, 2008). Nesse contexto, é necessário ressaltar a importância do uso do WhatsApp como uma ferramenta de suporte para a aula que permite "dinamizar a interação entre os agentes do contexto educacional” (ALENCAR et al., 2015, p. 789), visto que, além de um espaço para troca de informações sobre o curso, a retirada de dúvidas dos conteúdos, tarefas e trabalhos, pos-sibilita ao aluno, que é tímido ou possui dificuldades para argumentar em público, a oportu-nidade de se comunicar de forma escrita. Entendemos, assim, que o WhatsApp, no contexto de ensino-aprendizagem de línguas, acaba por também possibilitar o desenvolvimento da habilidade escrita.

\section{CAMINANDO POR PRODUCCIONES TEXTUALES}

Nesta subseção, interpretamos a criticidade dos alunos em fragmentos das suas produções escritas. Buscamos observar o domínio do aluno sobre o tema e seu posicionamento crítico frente a ele. Devido à restrição de páginas, optamos por interpretar o processo da produção escrita realizado com base em dois temas: violência de gênero e maternidade.

Para a construção de sentidos e a produção escrita do texto, o processo foi divido em três etapas. A primeira, antecessora ao ato da escrita, foi composta por estratégias como brainstorm (chuva de ideias), discussões orais, perguntas de pré-leitura e pré-escrita. Para dar suporte à primeira etapa, foram utilizados materiais de apoio autênticos, como matérias jornalísticas, crônicas, canções, vídeos do Youtube, curtas-metragens etc. O segundo momento foi marcado pela planificação e organização do texto, isto é, momento da construção de rascunhos com base na etapa anterior. A última etapa foi o momento de escrita, correção e reescrita, em que houve a verificação ortográfica e correção gramatical dos textos elaborados pelos alunos.

Iniciamos com o fragmento de Érika que reflete sobre a violência de gênero contra os homens e mulheres em um relacionamento. 
Quadro 1 - Texto produzido por Érika.

Cuando pensamos en una pareja donde las personas pasaran por situaciones de violencia tenemos la tendencia de suponer que es uma relación heterosexual. Quizá porque la mayoria de las noticias y investigaciones estatísticas estean dedicadas a discutir el machismo solamente en la perspectiva femenina, tiendo en la figura de la mujer la principal víctima. Eso es totalmente comprensible, pues historicamente las mujeres vivencian la opresión mucho antes do que los hombres. Ese dato puede ser comprobado por medio de la lectura del libro de Sérgio Lessa, llamado "Abaixo à Família Monogâmica", donde el autor discute el surgimiento de la propriedad privada en la historia de la humanidad, y los impactos que las mujeres tuvieron en sus vidas debido a ese nuevo contexto social.

Pero, es importante que nosotros también tengamos comprensión sobre la violencia vivenciada por los hombres. Delante de eso, entiendo que tanto los hombres homosexuales, cuanto los heterosexuales, pueden ser víctimas de la violencia domestica, principalmente al considerar que en las relaciones hay, generalmente, uno de los compañeros que acaban gustando más del outro, y infelizmente muchos son llevados a someter-se a determinadas situaciones para continuaren con su relación.

Entre los motivos que contribuen para que las personas se dejem ser dominadas por su pareja, destaco la verguenza por estar sendo víctima de violencia, la baja autoestima, y la dependencia afectiva. En lo que se refere a la verguenza por la violencia, pienso que nadie imagina o desea vivir en una relación donde es cotidianamente humillado, agredido y tratado como alguién que es incapaz de ser amado por otra persona.

Fonte: Produção coletada pelos autores da pesquisa, 2018.

Sobre a criticidade da aluna, embora o tema proposto tenha sido violência de gênero contra homens por suas parceiras, provenientes de matérias jornalísticas ${ }^{8}$, a aluna inicialmente apresenta que, quando se pensa em violência de gênero, logo se atribui a agressão ao homem, nunca à mulher. Segundo ela, as reportagens e dados estatísticos estão dedicos a discutir o machismo na perspectiva feminina, nunca na masculina. Justificado pela opressão vivenciada pelas mulheres historicamente, baseando seu argumento no autor Sérgio Lessa.

Érika ressalta a importância da compreensão sobre a violência sofrida pelos homens. Embora o material utilizado como suporte trouxesse apenas histórias sobre casais heteronormativos, a aluna apresenta um novo ponto de vista, quando expressa que também os homossexuais sofrem dessa violência. Informação que não estava presente no texto, nem nas discussões, uma nova informação. Em seu ponto de vista, em todas as relações, há sempre aquele que gosta mais que o outro, submetendo-se a determinadas situações para a continuação do relacionamento. A aluna ainda destacou como motivos para permanecer sofrendo a violência de gênero: a vergonha por ser vítima, a autoestima baixa e a dependência afetiva. Érika, em seu último argumento, utiliza a partícula de opinião (pienso) para dialogar com

${ }^{8}$ https://www.elconfidencial.com/sociedad/2010-04-24/nadie-habla-de-los-hombres-maltratados_395936. 
seu leitor, ao trazer o contexto real, compartilhado por ambos (MEYER, 2007), ao dizer que ninguém pode ser amado se viver numa relação com humilhação diária. Consideramos que a aluna se posicionou de maneira crítica, bem como fez Ana sobre maternidade, próxima produção escrita que interpretamos.

Observamos os conhecimentos que Ana possui sobre o tema, por meio dos argumentos apresentados sobre a maternidade, adoção e aborto, no texto a seguir.

Quadro 2 - Texto produzido por Ana.

Una cosa que yo pienso ser interesante es la diferenza con que los hombres y las mujeres son tratados cuando dicen que no quieren ser padres y madres. Los hombres no son vistos como personas insensibles o egoístas, pero, las mujeres son consideradas como personas que no tienen amor por los otros, mas solamente por ellas propias, porque no piensan en practicar la maternidad. Los argumentos religiosos son los principales que afirman eso, por entenderen que las mujeres fueran bienaventuradas por Dios para gerar hijos en sus vientres, y cuando se negan a hacerlo están cometendo pecados contra la gana divina.

Otro aspecto que pienso que también debe ser discutido es sobre la principal opción de la mayoría de las mujeres que desean ser madres y construyr sus familias: de tener hijos solamente biológicos, como se la opción de adoptar niños o adolescentes abandonados fuese menos verdadera, por ser un hijo nacido de otra mujer. Hijos son hijos independiente de sus orígenes, no hay eso de "es mi hijo de corazón", como tenemos la costumbre de decir en el Brasil. La ligación sanguínea es un mero detalle, pues lo que importa en el final de todo es el amor que se tiene, el respecto, la comprensión, y todo eso cualquier persona que se dedique puede ofrecer.

Llevando la discusión para otro elemento de la maternidad podemos destacar el aborto, que también es una opción de algunas mujeres que embarazan, y que no desean proseguir con la gravidez. Las situaciones en que eso ocurre son diversas, entonces solamente quien puede juzgar lo que aconteció son las propias personas envolvidas, pero, cuando hablamos de aborto estamos tratando de la vida de las mujeres, que de acuerdo con varias pesquisas, mueren todos los años en las diferentes regiones mundiales, principalmente en los países más pobres. No es una cuestión de moralidad, y sí de salud pública, porque no afecta a pocas mujeres, pero a muchas.

Fonte: Produção coletada pelos autores da pesquisa.

No primeiro parágrafo, a aluna expõe seu ponto de vista sobre a forma de tratamento recebida por mulheres e homens com relação à maternidade indesejada. Em sua opinião, enquanto a mulher é vista como insensível e egoísta, pessoas sem empatia, os homens são vistos com outros olhos, com outra visão. E, para embasar seu ponto de vista, cita os religiosos como principais perpetuadores dessa visão, por entenderem que as mulheres são bem-aventuradas para a procriação e, quando se negam a isso, são acusadas de pecadoras. Além disso, percebemos nos trechos "Los argumentos religiosos son los principales que afirman eso" e "como tenemos 
la costumbre de decir en el Brasil", a tentativa da aluna em convencer seu leitor sobre o consentimento das regras estabelecidas pela sociedade como trabalho da família, das religiões, das escolas e meios de produção (JANKS, 2016, p. 29), visto que é na língua e pela linguagem que há a mobilização das significações para manter as coisas como estão.

No segundo parágrafo, Ana reflete sobre a maternidade biológica e a adoção. Para a aluna, as mulheres assumem que adotar crianças e adolescentes abandonados é considerado pela sociedade como menos verdadeiro que a maternidade biológica, devido ao fato do filho(a) ser fruto de outros. Em seu ponto de vista, filhos são filhos, independente da sua origem, não havendo o famoso "filho do coração", termo comumente utilizado no Brasil. Para ela, a ligação sanguínea é um mero detalhe, pois o que importa é o amor, o respeito, a compreensão, finalizando que esses sentimentos podem ser oferecidos por qualquer pessoa.

Ainda sobre a maternidade, após seus dois posicionamentos anteriores, a aluna, no terceiro parágrafo produzido, levanta como ponto importante para discussão o aborto, como uma opção às mulheres que engravidam e não querem dar continuidade ao processo. Para ela, as situações que geram o aborto são diversas. Assim, somente os progenitores devem avaliar as ações a serem tomadas para a resolução da situação, não havendo espaço para outros, pois o tema relaciona-se com a vida de mulheres que, de acordo com pesquisas, morrem todos os anos em diferentes regiões do mundo, principalmente nos países mais pobres. Para ela, o aborto não é questão de moralidade, mais sim de saúde pública, pois não afeta poucas mulheres, mais muitas.

Constatamos que ambas as alunas demonstram uma atitude responsiva ativa (BAKHTIN, 1992), visto que, como nos esclarece o autor:

a compreensão de uma fala viva, de um enunciado vivo é sempre acompanhada de uma atitude responsiva ativa (conquanto o grau dessa atividade seja muito variável); toda compreensão é prenhe de resposta e, de uma forma ou de outra, forçosamente a produz: [...] o ouvinte que recebe e compreende a significação de um discurso adota simultaneamente, para com esse discurso, uma atitude responsiva ativa: ele concorda ou discorda (total ou parcialmente), completa, adapta, apronta-se para executar (BAKHTIN, 1992, p. 290).

Afinal, para o autor, todo ato de compreensão é uma resposta, ou seja, quando as alunas tomam a atitude de se posicionarem ideologicamente sobre os temas, estão se posicionando responsiva-ativamente sobre o que acreditam, com relação à maternidade e a violência de gênero. Essas crenças advêm de concepções construídas a partir da experiência de leituras de outros textos e de diálogos com outras pessoas. Para Fuza e Menegassi (2006, apud LINS; SANTOS, 2010), esta atitude responsiva pode ser interna, quando o autor conversa consigo mesmo sobre sua produção textual, ou externa quando o autor escreve para que suas ideias 
sejam vistas. Além disso, para Lins e Santos (2010), compreender não é apenas o posicionamento discursivo sobre um fato discursivo, mas é a apropriação dos discursos produzidos por outros para constituição de um enunciado, para, enfim, contra-argumentar o discurso do outro com suas próprias palavras. No caso dos textos analisados, observamos que as alunas expressam posicionamentos discursivos externos por meio das produções textuais. Entretanto, a partir da atitude responsiva externa, podemos acessar o seu interior por meio dos posicionamentos particulares apresentados no ato composicional.

\section{AVALIAÇÃO DO PROCESSO DE ENSINO}

Comentários dos alunos no final do semestre revelam o processo por eles vivenciados conosco. Abaixo, seguem alguns que interpretamos.

Figura 2 - Capturas de tela de conversas com os alunos.

\begin{tabular}{|c|c|}
\hline $\begin{array}{l}\text { Al largo del curso básico de español } \\
\text { yo pensé que las discusiones que }\end{array}$ & $\begin{array}{l}\text { estao agora seguras com criprogranila de ponta } \\
\text { ponta. Toque para obter mais informaçōes. }\end{array}$ \\
\hline $\begin{array}{l}\text { más serian hechas eran aquellas so- } \\
\text { bre la gramática española, las reglas } \\
\text { cultas de la lengua, y todo aquillo } \\
\text { que tienesse relación con el aspecto } \\
\text { formal del idioma. Eso también } \\
\text { ocurrió, pero en las clases el profesor } \\
\text { tenía una preocupación en debater } \\
\text { temas con una perspectiva crítica, } \\
\text { que hiciessen los alumnos reflejaren } \\
\text { sobre sus vidas, los preconceptos } \\
\text { y las situaciones que envolvesen } \\
\text { opiniones diferentes de las suyas. } \\
\text { Y eso es muy importante, pues creo } \\
\text { que no es suficiente solamente dete- } \\
\text { nerse a enseñar contenidos formales } \\
\text { de la lengua española, y síampliar } \\
\text { el conocimiento para aspectos que } \\
\text { hacen parte del cotidiano. También } \\
\text { pienso que la criticidad contribui para } \\
\text { el desarrollo de la produción textual, } \\
\text { pues hace los estudiantes teneren } \\
\text { gue }\end{array}$ & $\begin{array}{l}\text { Básico } 3 \text { CCC } \\
\text { A experiência no básico } 3 \text { em } \\
\text { espanhol da casa de cultura foi } \\
\text { bastante satisfatória, pois além de } \\
\text { elencar assuntos da gramatica da } \\
\text { língua espanhola, um dos pontos do } \\
\text { curso também foi a produção textual } \\
\text { e discussão desses textos em sala } \\
\text { de aula. Os textos discutidos em sala } \\
\text { de aula, não foram textos aleatórios, } \\
\text { e sim textos de assuntos que estão } \\
\text { no nosso cotidiano, e que são } \\
\text { importantes de se problematizar. } 0 \\
\text { intercambio dentro da sala de aula foi } \\
\text { interessante, pois além dos alunos } \\
\text { da graduação, alunos do ensino } \\
\text { médio e da comunidade estavam } \\
\text { inseridos na turma, e podemos juntos } \\
\text { descontruir alguns assuntos que são } \\
\text { naturalizados em nossa sociedade } \\
\text { pelo senso comum. }\end{array}$ \\
\hline
\end{tabular}

Fonte: Autores, 2018.

No comentário da esquerda, Marta reconheceu o nosso propósito: discussão temática é anterior a explicação linguística. Isto é, discutiu-se a importância do tema e, em seguida, o estudo formal da língua espanhola foi trabalhado. Para ela, foi muito importante debater temas a partir de perspectivas críticas, levando os alunos a refletirem sobre suas vidas e sobre os preconceitos, pois crê que o ensino formal da língua não é suficiente. É necessário também ampliar os conhecimentos para aspectos que fazem parte do cotidiano, para que o sujeito, através da linguagem, possa "atuar nas diferentes práticas sociais, de modo a posicionar-se enquanto sujeito crítico e provar mudanças se assim desejar” (LAMBERT; SOUZA, 2018, p. 232).

No comentário de Pedro, à direita, identificamos o reconhecimento acerca do trabalho de produção escrita sobre os temas do cotidiano. Outro ponto importante, segundo ele, foi o 
intercâmbio dentro da sala de aula, entre os alunos da graduação e de alunos de ensino médio, possibilitando a todos a desconstrução de alguns assuntos que são naturalizados na sociedade pelo senso comum. Segundo Mattos e Valério (2010), um processo de ensino-aprendizagem, baseado no letramento crítico, significa avançar em relação ao tipo de educação que perpetua as relações de poder existentes nas sociedades, promove a conformação do indivíduo e priva o sujeito dos questionamentos em torno das relações de poder. Pressupõe desenvolver possibilidades de ensino voltadas para o empoderamento e a ação do alunado na sociedade, além de capacitá-los para agir sobre as relações de poder que perpetuam as desigualdades e a exclusão social (SANTOS; IFA, 2013).

\section{CoNSIDERAÇõES FINAIS}

A importância deste estudo revelou que é possível, frutífero e significativo o ensino língua adicional dentro de perspectivas mais críticas, combinadas com estratégias de desenvolvimento das habilidades linguísticas e discursivas, visto que o ensino não se sujeita tão somente a saber regras gramaticais e ortográficas. Acreditamos que a aprendizagem da língua adicional deve estar vinculada às práticas sociais da linguagem. Para isso, precisamos proporcionar interação para que os alunos percebam a importância do seu engajamento e do engajamento do outro para agir no mundo social.

Compreendemos também que, como professores em contínua formação, é muito complicado e descontextualizado ensinar uma língua adicional dissociada das questões linguísticas, culturais e identitárias (TEIXEIRA; RIBEIRO, 2012). Realçamos, portanto, que o ensino-aprendizagem precisa levar em consideração o contexto, as situações reais de uso da língua, gerando a percepção da importância desse uso para a interação social e, também, para a formação cidadã de todos os envolvidos.

Com o embasamento do Letramento Crítico, possibilitamos aos alunos aprender a problematizar as palavras, estas que estão sempre influenciadas pelo mundo, pelo uso e pela significação atribuída às pessoas. É perceber que os discursos "são ideológicos, situados e, por isso, contestáveis" (IFA; STELLA, 2014).

Além disso, quando refletimos criticamente, podemos vivenciar uma transformação de conduta, além de poder observar e atuar de um modo que anteriormente não era possível. A reflexão não se volta para o ponto de partida, movendo-se em um contínuo fluir transformador da experiência passada, surgindo uma nova temporalidade, uma nova compreensão pessoal e uma nova dimensão relacional e situacional, uma vez que, como seres humanos, nossas experiências são histórias de transformações contínuas na reflexão e na ação (ARAGAO, 2008).

No tocante à perspectiva da escrita como processo, compreendemos que os alunos, por meio das produções escritas, além de enriquecerem seus conhecimentos sobre os aspectos 
linguísticos e formais da língua espanhola, refletiram e se posicionaram criticamente sobre os temas propostos nas aulas pela leitura, discussão, escrita e reescrita, como também expressaram sentimentos, questionamentos, interagiram com os leitores, socializaram argumentos, entre outros. Desta forma, a atividade da escrita deixa de ser individual, caracterizada pela elaboração frasal, de períodos e orações, e torna-se ação social (MENICONI, 2017).

Por fim, esta pesquisa nos permitiu, como professores em continua formação, refletir sobre o fazer docente para uma melhor prática pedagógica, uma vez que esse fazer requer constantes problematizações, busca por respostas, abandono de métodos e "orientação constituída de conhecimentos e teorias, a partir da reflexão crítica da prática docente" (SANTOS; IFA, 2013, p. 10). É o entendimento que não estamos prontos e acabados, mas em um processo continuo de formação que nunca termina, é um processo permanente.

\section{REFERÊNCIAS}

ALENCAR, G. A. et al. Whatsapp como ferramenta de apoio ao ensino. In: CONGRESSO BRASILEIRO DE INFORMÁTICA NA EDUCAÇÃO, 2015, Maceió-AL. Anais [...].Porto AlegreRS: Sociedade Brasileira de Computação, p. 787-795, 2015.

ARAGAO, R. Emoções e pesquisa narrativa: transformando experiências de aprendizagem. Rev. bras. linguist. apl., v. 8, n. 2, p. 295-320, 2008.

ARAUJO, J. N. M. Formação inicial de professores de Espanhol no Projeto Casas de Culturano Campus: ecologia dos saberes e letramento crítico. Dissertação (Mestrado em Letras e Linguística) - Faculdade de Letras, Universidade Federal de Alagoas. Alagoas, p.115. 2018.

BAKHTIN, M. Estética da criação verbal. São Paulo: Martins Fontes, 1992.

BRASIL. Secretaria de Educação Fundamental. Parâmetros curriculares nacionais: terceiro e quarto ciclos do ensino fundamental: língua estrangeira / Secretaria de Educação Fundamental. Brasília: MEC/SEF, 1998.

BROKES, A.; GRUNDY, P. Beginning to write writing activities for elementary an intermediate learner. Cambrige: Cambrigde University Press, 1988.

CAMPBELL, R. P. B.; IFA, S. A formação crítica de alunos e professores de inglês: uma relação entre escrita, argumentação e letramento crítico. ISSN: 1519-5392. Extretextos (UEL), v. 16, n. 2, p. 127-152, 2016.

CLANDININ, D. J.; CONNELLY, F. M. Pesquisa narrativa: experiência e história em pesquisa qualitativa. Tradução: Grupo de Pesquisa Narrativa e Educação de Professores ILEEI/UFU. Uberlândia: EDUFU, 2011. 
FEITOSA, Q. D; MENICONI, F. C; IFA, S. A argumentação em produções textuais de alunos de língua espanhola de um projeto de extensão universitária. Revista Leitura, v. 1, p. 106-119, 2020.

FLOWER, L; HAYES, J. R. A cognitive process theory of writing. College Composition and Communication, 1981. Disponível em: http://ourses.johnmjones.org/ENGL605/wp- content/ uploads/2012/05/Flower-and-Hayes-Cognitive-Process.pdf. Acesso em: 1 dez. 2019.

FLOWER, L.; HAYES, J. La teoría de la redacción como proceso cognitivo. En Textos en contexto n. 1. Buenos Aires: Lectura y Vida, 1996.

JANKS, H. Panorama sobre letramento crítico. In: JESUS, D. M.; CARBONIERI, D. (Org.). Práticas de Multiletramentos e Letramento Crítico: Outros sentidos para a Sala de aula de Línguas. Campinas, SP: Pontes Editores, p. 21-39, 2016.

KOCH, I.; TRAVAGLIA, O. Texto e coerência. São Paulo: Cortez, 1992.

LAMBERT, W. R. G.; SOUZA, G. R. A promoção da educação ambiental na aula de portugues: contribuições do letramento crítico. Hon No Mushi - Estudos Multidiscuplinares Japoneses, v. 3, p. $226-240,2018$.

LIBÂNEO, J. C. Democratização da escola pública: pedagogia crítico-social dos conteúdos. São Paulo, Loyola, 1985.

LINS, N; SANTOS, M. F. O. A compreensão responsiva ativa no gênero do discurso dramatização. Letra Magna, v. 06, p. 1-12, 2010.

LOPES, P. A. O espanhol como língua estrangeira segundo aprendizes do ensino médio. Domínios de Lingu@gem, v. 14, n. 1, p.1-29, 2020.

MADRIGAL ABARCA, M. La escritura como proceso: metodología para la enseñanza de la expresión escrita en español como lengua extranjera. Filología y Linguística, v. 34, p. 127-141, 2008.

MARCUSCHI, L. A. Produção textual, análise de gêneros e compreensão. São Paulo: Parábola, 2008.

MATTOS, A. M. A; VALÉRIO, K. M. Letramento crítico e ensino comunicativo: lacunas e intersecções. RBLA, v.10, n.1, pp. 135-158, 2010.

MENICONI, F. C. Escrita em língua espanhola: é possível produzir textos nas fases iniciais do ensino-aprendizagem de um novo idioma? 1. ed. Maceió: Edufal e Imprensa Oficial Graciliano Ramos, 2017.

MEYER, M. A retórica. São Paulo: Ática, 2007.

MOREIRA JÚNIOR, R. S. Português como Língua Adicional e Letramento Crítico: ensinoaprendizagem com participantes falantes de outras línguas na Universidade Federal de 
Alagoas. Dissertação (Mestrado em Letras e Linguística) - Faculdade de Letras, Universidade Federal de Alagoas. Alagoas, 190f, 2016.

MOTTA, A. P. F. O letramento crítico no ensino/aprendizagem de língua inglesa sob a perspectiva docente. Londrina, 2008. Disponível em: http://www.diaadiaeducacao.pr.gov. br/portals/pde/arquivos/379-4.pdf. Acesso: 22 nov. 2019.

MULIK, K. B. Letramento crítico e interculturalidade nas aulas de língua inglesa na educação de jovens e adultos. REVISTA X, v. 2, p. 11-19, 2011.

SAHAGOFF, A. P. C. Pesquisa Narrativa: uma metodologia para compreender a experiência humana. In: XI SEPesq, Porto Alegre, v. XI, 2015.

SANTOS, R. R. P.; IFA, S. O letramento crítico e o ensino de inglês: reflexões sobre a prática do professor em formação continuada. The Especialist, v. 34, p. 1-23, 2013.

STELLA, P.; IFA, S. Uma perspectiva letrada para o referencial curricular de línguas estrangeiras em alagoas: questões e desafios. In: STELLA, P. R. et al. (org.). Transculturalidade e descolonialidade nos estudos em inglês no Brasil. Maceió, AL: Edufal, 2014.

TAPIA, J. A.; FITA, E. C. A motivação em sala de aula. O que é, como se faz? São Paulo: Edições Loyola. 8. ed. 2009.

TEIXEIRA, C. S.; RIBEIRO, Maria D’Ajuda Alomba Ribeiro. Ensino de língua estrangeira: concepções de língua, cultura e identidade no contexto ensino/aprendizagem. Revista Linha D’agua, p. 182-201, 2012.

TILIO, R. Língua estrangeira moderna na escola pública: possibilidades e desafios. Educ. Real, V. 39, n. 3, p. 925-944, 2014.

Recebido para publicação em: 20 abr. 2021. Aceito para publicação em: 13 jul. 2021. 